\title{
Apatite fission-track analysis: Progress by effective track etch time
}

\author{
NOVAKOVA LUCIE ${ }^{1,2}$, RAYMOND JONCKHEERE ${ }^{2}$, \\ BASTIAN WAUSCHKUHN ${ }^{2}$ AND LOTHAR \\ RATSCHBACHER ${ }^{2}$
}

${ }^{1}$ Czech Academy of Sciences, IRSM

${ }^{2}$ Institute of Geology, TU Bergakademie Freiberg

Presenting Author: lucie.novakova@irsm.cas.cz

Apatite fission track dating and T,t-modelling are established thermochronological tools [1]. Over time, various factors affecting the track counts and length measurements were identified and corrected, the most important being the apatite's chemical composition and the orientation of the etched grain surface and the individual confined tracks [2]. Nevertheless, there is no generally accepted etch protocol or complete understanding of possible metrological and selection biases associated with a specific protocol.

Step-etching experiments with common etchants pointed out effects of the etching concentration, duration, and temperature on the measured track lengths, which cannot be ignored [3, 4]. We employed a step-etch approach to overcome these problems, measuring the $c$-axis angle, length, width, and dip of each individual confined track after $10 \mathrm{~s}, 20 \mathrm{~s}$ and $30 \mathrm{~s}$ immersion in $5.5 \mathrm{M} \mathrm{HNO} 3$ at $21{ }^{\circ} \mathrm{C}$. From the width data, we determine the rate of track widening [5] and use it to calculate the effective etch time, i.e. the actual time that each confined track has been etched. The effective etch time is equal to the immersion time minus the time needed for the etchant to get to the confined track. Our results show that the mean confined track length increases with effective etch time.

Our current geological investigations are concerned with the exhumation of the Naab Mountains on the western border of the Bohemian Massif. For T,t-modelling, we first determine if, and for which effective etch times, the fossil tracks exhibit the length anisotropy predicted by the theoretical models based on induced tracks. We then select the corresponding effective-etch time window for the induced tracks. Our approach assumes that this eliminates at least part of the systematic etch-protocol related effects and increases the accurateness and resolution of the resulting T,t-paths.

References

[1] Malusà and Fitzgerald (2019), Fission-Track Thermochronology and its Application to Geology, pp 393.

[2] Green et al. (1986), Chemical Geology 59, 237-253.

[3] Jonckheere et al. (2017), American Mineralogist 102, 987996.

[4] Tamer et al. (2019), American Mineralogist 104(10), 14211435.

[5] Aslanian et al. (2021), American Mineralogist. In press. 